
\title{
Gemcitabine-based chemotherapy as a viable option for treatment of advanced breast cancer patients: a meta-analysis and literature review
}

\author{
Zhibo Xie ${ }^{1, *}$, Yifan Zhang ${ }^{2, *}$, Chen Jin' ${ }^{1}$ and Deliang Fu ${ }^{1}$ \\ ${ }^{1}$ Department of Pancreatic Surgery, Pancreatic Disease Institute, Huashan Hospital, Shanghai Medical College, Fudan \\ University, Shanghai 200040, China \\ ${ }^{2}$ Department of Plastic and Reconstructive Surgery, Shanghai Ninth People's Hospital, School of Medicine, Shanghai Jiao \\ Tong University, Shanghai 200011, China \\ *These authors contributed equally to this work and should be considered as co-first authors \\ Correspondence to: Yifan Zhang, email: dr.yifanzhang@gmail.com \\ Deliang Fu, email: surgeonfu@163.com
}

Keywords: gemcitabine; advanced breast cancer; chemotherapy; tumor response; adverse events

Received: May 10, $2017 \quad$ Accepted: November 29, $2017 \quad$ Published: December 19, 2017

Copyright: Xie et al. This is an open-access article distributed under the terms of the Creative Commons Attribution License 3.0 (CC BY 3.0), which permits unrestricted use, distribution, and reproduction in any medium, provided the original author and source are credited.

\section{ABSTRACT}

This meta-analysis was designed to compare the efficacy and safety of gemcitabine-based regimens for the treatment advanced breast cancer (ABC). Altogether 15 studies involving 8195 ABC patients were retrieved for analysis. Compared with non-gemcitabine-based chemotherapies, patients receiving gemcitabine-based therapy exhibited better overall survival (OS), progression free survival (PFS), and objective response rate (ORR) (HR = 1.12, $95 \%$ CI 1.05 to $1.19 ; \mathrm{HR}=1.16,95 \%$ CI 1.03 to $1.30 ; \mathrm{HR}=1.14,95 \%$ CI 1.04 to 1.24 ). Grade $3 / 4$ hematologic toxicity was significantly high but manageable in gemcitabine-based groups. Subgroup analysis revealed that patients with first-line gemcitabine-based chemotherapy had better OS (HR = 1.19, 95\% CI 1.07 to 1.32), PFS (HR = 1.17, 95\% CI 1.08 to 1.27), and ORR ( RR = 1.16, 95\% CI 1.02 to 1.32). In addition, additional gemcitabine chemotherapy also showed better OS (HR = 1.17, $95 \% \mathrm{CI}$ 1.06 to 1.30$)$, PFS (HR = 1.20, 95\% CI 1.11 to 1.30) and ORR (RR = 1.23, $95 \% \mathrm{CI}$ 1.06 to 1.42 ) than gemcitabine replacement therapy. Furthermore, patients receiving gemcitabine-taxanes-based regimens had better OS (HR = 1.17, 95\% CI 1.06 to 1.28), PFS (HR = 1.12, 95\% CI 1.04 to 1.20) and ORR (RR = 1.17, 95\% CI 1.01 to 1.35$)$ than patients with non-gemcitabine-taxanes-based chemotherapy. These findings indicate that gemcitabine combination regimens could serve as a promising regimen for $A B C$ patients, though increased hematologic toxicity should be considered with caution.

\section{INTRODUCTION}

Breast cancer is one of the most prevalent cancers, causing approximately half a million deaths per year worldwide [1]. Among women with breast cancer in Western countries, 30\%-40\% had advanced breast cancer (ABC) [2], in whom the median survival is 2-3 years, and the 5-year survival is $5-10 \%$ [3]. The principal goal of current therapies for the treatment of $\mathrm{ABC}$ patients is to seek a longer progression-free survival (PFS) and better symptom relief without increasing toxicity or compromising the quality of life (QoL) [4].

Among the chemotherapeutic agents currently available for the treatment of ABC, anthracyclines and taxanes are considered the most active and represent widely used treatment options $[5,6]$. However, ABC is likely to progress due to primary or acquired resistance to these chemotherapy drugs. In addition, chemotherapy regimens containing anthracyclines and/or taxanes are now often considered as the standard option for 
adjuvant treatment of early breast cancer, especially in high-risk women, thus limiting their use in patients who subsequently develop disease relapse [7, 8].

New cytotoxic treatments for disseminated disease, such as gemcitabine, capecitabine, and vinorelbine, are now available for patients who have been previously treated with anthracyclines and taxanes [9-11]. Gemcitabine (Gemzar; $2^{\prime}, 2^{\prime}$-difluorodeoxycytidine) is a pyrimidine antimetabolite and a specific analogue of deoxycytidine widely used in many kinds of solid tumors or neoplastic hematologic disorders. In $\mathrm{ABC}$ patients, the clinical outcomes of trials evaluating combination regimens containing gemcitabine are inconsistent. Many clinical trials with large sample size discovered that combination regimens containing gemcitabine could prolong both overall survival (OS) and PFS without increasing the occurrence of serious adverse events (ADEs) $[12,13]$. Other medical centers argued that OS and PFS were similar between patients with or without gemcitabine regimens, and that gemcitabine was also associated with serious ADEs in individual cases [14]. The above results show that there are controversies about the benefit of gemcitabine-based combination regimens. In addition, some studies used gemcitabine as the first-line treatment [15], while studies used it as the second-line treatment in $\mathrm{ABC}$ patients who were pretreated with anthracycline- or taxane [16]. What's more, chemotherapy regimens for $\mathrm{ABC}$ patients are multifarious in different studies. In some studies, the chemotherapy regimen was used as a control group, and gemcitabine plus the same chemotherapy regimen as the experimental group $[12,17,18]$. In other studies, researchers used gemcitabine combination regimens as the experimental group, and another totally different chemotherapy regimen as the control group [19].

Given the above confusion, it is necessary to find out the significance of gemcitabine in $\mathrm{ABC}$ patients and testify whether gemcitabine-based combination regimens will bring more benefits to these patients. In the current study, we focused on gemcitabine-based chemotherapies versus non-gemcitabine-based therapies for the treatment of $\mathrm{ABC}$.

\section{RESULTS}

\section{Search strategy and selection criteria}

Initial searching of literature databases and trial registries revealed 479 published clinical trials and 66 registered ones (Figure 1). After removing 7 duplicates, 538 potentially eligible trials were left, of which 517 trials were excluded after reviewing the abstracts because the study design or outcome data did not satisfy the inclusion criteria. After reading the full text of the remaining 21 trials, 6 studies [20-25] were further excluded. The study of Feher et al. [20] was excluded because they used gemcitabine monotherapy in the experimental group, knowing that we only included studies with combination regimens containing gemcitabine. In addition, they enrolled postmenopausal women (aged 60 or older), which may produce selection bias for our analysis. The study of Park et al. [22] was also excluded because their patients were randomized to receive a combination of gemcitabine and vinorelbine or gemcitabine until disease progression followed by vinorelbine monotherapy. In Tomova et al.'s study [25], the patients were randomized to receive gemcitabine plus docetaxel administered intravenously for a total of eight cycles or four cycles of docetaxel followed by four cycles of gemcitabine. In Seidman et al.'s study [23], a crossover design was used. In above 3 studies $[22,23,25]$, gemcitabine was used in both experimental and control groups, which was not eligible for our analysis. In Moinpour et al.'s study [21], survival data were not available. In another study published in 2014 by Seidman et al. [24], a pooled result was from Chan et al.'s study [26] and Seidman et al.'s study [23]. For these reasons, we excluded above six studies and enrolled the rest 15 studies $[12-18,26-33]$ in our systematic review (The Selection flow was is shown in Figure 1).

Altogether 15 studies [12-18, 26-33] with 8195 ABC patients were finally enrolled in our analysis (Table 1). Of them, 12 studies [12-18, 26, 29-31, 33] had 2-arm design, and the remaining 3 studies [27, 28, 32] had 3 arms design. In addition, five studies [16, 26, 29-31] used gemcitabine as second-line chemotherapy, and the others used gemcitabine as first-line chemotherapy. Nevertheless, seven studies [12, 13, 15, 17, 18, 29, 31] used additional gemcitabine chemotherapy. With respect to different chemotherapy regimens in different studies, the gemcitabine combined taxanes chemotherapy regimen was most commonly used in nine studies $[12,13,15,17$, $18,26,31-33]$ of the 15 included studies.

\section{Survival and tumor response}

In the three studies with 3-arm design [27, 28, 32], survival data were presented as survival curves, and therefore we only included studies with 2-arm design for survival analysis. But as these three studies provided objective response rate (ORR) data, they were eligible and included for ORR analysis.

\section{Overall survival}

We first conducted meta-analysis about OS and found that nine studies [12-18, 26, 29-31, 33] with two-arm design evaluated OS. Pooled results showed that combination regimens containing gemcitabine significantly prolonged the $\mathrm{OS}$ of $\mathrm{ABC}$ patients [hazard ratio $(\mathrm{HR})=1.14,95 \%$ confidence interval $(\mathrm{CI}) 1.04$ to 1.24)] (Figure 2A).

Moreover, the OS data were also reported in studies with 3-arm design. In Fountzilas et al.'s study [27], the median survival was 29.9 months in patients 
using paclitaxel and carboplatin, 26.9 months in patients using docetaxel and gemcitabine, and 41.0 months in patients using monotherapy of paclitaxel $(P=0.037)$. Nevertheless, Swain et al. [32] also presented the OS data. They randomized patients to receive six cycles of docetaxel (T), doxorubicin (A), and cyclophosphamide (C) (TAC), four cycles of dose-dense (DD) doxorubicin and cyclophosphamide followed by four cycles of $\mathrm{DD}$ paclitaxel $(\mathrm{P})(\mathrm{AC} \rightarrow \mathrm{P})$, or $\mathrm{DD} \mathrm{AC} \rightarrow \mathrm{P}$ with four cycles of gemcitabine $(\mathrm{G})$ added to the DD paclitaxel (DD $\mathrm{AC} \rightarrow \mathrm{PG}$ )and found that $\mathrm{OS}$ was similar between patients with $\mathrm{AC} \rightarrow \mathrm{PG}$ and patients with $\mathrm{AC} \rightarrow \mathrm{P}(\mathrm{HR}=0.85$, $P=0.130)$ or between patients with $\mathrm{AC} \rightarrow \mathrm{PG}$ and patients with TAC $(\mathrm{HR}=0.86, P=0.170)$. They showed that combination regimens containing gemcitabine did not bring significant benefits to ABC patients in terms of OS.

\section{Progression free survival}

Pooled results from 12 studies with two-arm design [12-18, 26, 29-31, 33] revealed that patients received combination regimens containing gemcitabine had a significant better PFS (HR $=1.12$, 95\% CI 1.05 to 1.19 ) (Figure 2B).

In studies with 3-arm design, Fountzilas et al. [27] found that PFS was similar between their 3 groups (mean PFS: 11.5 months for paclitaxel and carboplatin; 10.4 months for docetaxel and gemcitabine; 11.4 months for paclitaxel; $P=0.570$ ). Similarly, Gómez et al. [28] found that there was no significant difference in PFS between patients in three arms (mean PFS: 9.1 months for lapatinib and capecitabine; 7.0 months for lapatinib and vinorelbine; 6.8 months for lapatinib and gemcitabine; $P=0.476$ ). Swain et al. [32] also showed a similar PFS between patients in three arms $(\mathrm{AC} \rightarrow \mathrm{PG} v s . \mathrm{TAC}, \mathrm{HR}=0.93$, $P=0.390 ; \mathrm{AC} \rightarrow \mathrm{PG} v s . \mathrm{AC} \rightarrow \mathrm{P}, \mathrm{HR}=1.07, P=0.410)$.

\section{Objective response rate}

Altogether 11 studies including 10 studies with twoarm design [12-18, 26, 29, 30, 33] and 1 study with threearm design [28] presented the outcome of ORR and found
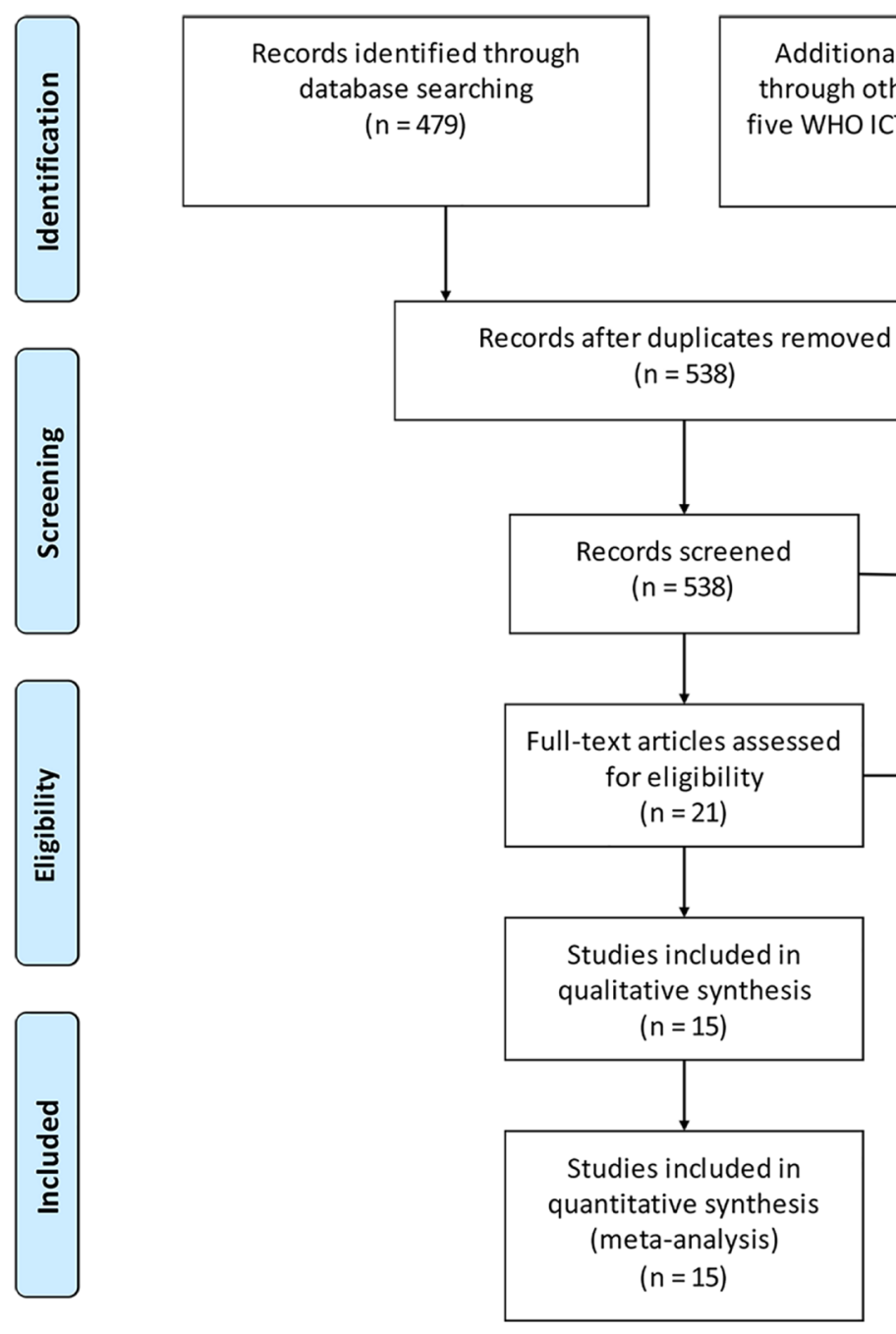

Additional records identified through other sources including ve WHO ICTRP Primary Registers $(n=66)$
壱
Records excluded: inadequate randomized trials, systematic review and meta-analysis ( $n=517)$

Full-text articles excluded, with reasons: inadequate groups, without survival data, and duplicated data $(n=6)$

Figure 1: A flow diagram of the search strategy. 
Table 1: Baseline characteristics of included studies

\begin{tabular}{|c|c|c|c|}
\hline Study & Arm & Patients, $n$ & Regimens \\
\hline \multirow{2}{*}{$\begin{array}{l}\text { Albain et al. } \\
2008\end{array}$} & $\mathrm{Gem} / \mathrm{Pac}$ & 266 & Gem $1250 \mathrm{mg} / \mathrm{m}^{2}$ i.v. $\mathrm{d}_{1,8}$, Pac $175 \mathrm{mg} / \mathrm{m}^{2}$ i.v. $\mathrm{d}_{1}$, q21d \\
\hline & $\mathrm{Pac}$ & 263 & Pac 175 mg/m² i.v. $d_{1}$, q21d \\
\hline \multirow{2}{*}{$\begin{array}{l}\text { Amadori et al. } \\
2013\end{array}$} & $\mathrm{Gem} / \mathrm{Nvb}$ & 61 & Gem $1200 \mathrm{mg} / \mathrm{m}^{2}$ i.v. $\mathrm{d}_{1,8}, \mathrm{Nvb} 30 \mathrm{mg} / \mathrm{m}^{2}$ i.v. $\mathrm{d}_{1,8}, \mathrm{q} 21 \mathrm{~d}$ \\
\hline & $\mathrm{Pem} / \mathrm{Cbp}$ & 64 & Pem $600 \mathrm{mg} / \mathrm{m}^{2}$ i.v. $\mathrm{d}_{1}, \mathrm{Cbp}$ an AUC of 5 i.v. $\mathrm{d}_{1}, \mathrm{q} 21 \mathrm{~d}$ \\
\hline \multirow[t]{2}{*}{$\begin{array}{l}\text { Brufsky et al. } \\
2011\end{array}$} & $\mathrm{Gem} / \mathrm{Pac} / \mathrm{Beva}$ & 93 & $\begin{array}{l}\text { Pac } 90 \text { mg/m² i.v. } \mathrm{d}_{1,8,15} \text {, Beva } 10 \mathrm{mg} / \mathrm{kg} \text { i.v. } \mathrm{d}_{1,15} \text {, Gem 1500mg, } \\
\qquad \mathrm{d}_{1,15}, \mathrm{q} 28 \mathrm{~d}\end{array}$ \\
\hline & $\mathrm{Pac} / \mathrm{Beva}$ & 94 & Pac 90 mg/m² i.v. $d_{1,8,15}$, Beva 10 mg/kg i.v. $d_{1,15}$, $\mathrm{q} 28 \mathrm{~d}$ \\
\hline \multirow[t]{2}{*}{ Chan et al. 2009} & Gem/Doc & 152 & Gem $1000 \mathrm{mg} / \mathrm{m}^{2}$ i.v. $\mathrm{d}_{1,8}$, Doc $75 \mathrm{mg} / \mathrm{m}^{2}$ i.v. $\mathrm{d}_{1}$, q21d \\
\hline & Cap/Doc & 150 & Cap $1250 \mathrm{mg} / \mathrm{m}^{2}$ bid $\mathrm{d}_{1-14}$, Doc $75 \mathrm{mg} / \mathrm{m}^{2}$ i.v. $\mathrm{d}_{1}$, q21d \\
\hline \multirow{3}{*}{$\begin{array}{l}\text { Fountzilas et al. } \\
2009\end{array}$} & $\mathrm{Pac} / \mathrm{Cbp}$ & 136 & Pac $175 \mathrm{mg} / \mathrm{m}^{2}$ i.v. $\mathrm{d}_{1}$, Cbp an AUC of $6 \mathrm{~d}_{1}, \mathrm{q} 3 \mathrm{w}$ for 6 cycles \\
\hline & Gem/Doc & 134 & Gem $1000 \mathrm{mg} / \mathrm{m}^{2}$ i.v. $\mathrm{d}_{1,8}$, Doc $75 \mathrm{mg} / \mathrm{m}^{2}$ i.v. $\mathrm{d}_{8}$, q3w for 6 cycles \\
\hline & $\mathrm{Pac}$ & 136 & Pac $80 \mathrm{mg} / \mathrm{m}^{2}$ i.v., q1w for 12 cycles \\
\hline \multirow{3}{*}{$\begin{array}{l}\text { Gómez et al. } \\
2016\end{array}$} & Lap/Cap & 51 & Lap $1250 \mathrm{mg}$ p.o. $\mathrm{d}_{1-14}$, Cap $2000 \mathrm{mg} / \mathrm{m}^{2}$ p.o. $\mathrm{d}_{1-14}$ \\
\hline & Lap/ Nvb & 45 & Lap $1250 \mathrm{mg}$ p.o. $\mathrm{d}_{1-14}, \mathrm{Nvb} 25 \mathrm{mg} / \mathrm{m}^{2}$ i.v. $\mathrm{d}_{1,8}$ \\
\hline & Lap/Gem & 46 & Lap $1250 \mathrm{mg}$ p.o. $\mathrm{d}_{1-14}$, Gem $1000 \mathrm{mg} / \mathrm{m}^{2} \mathrm{~d}_{1,8}$ \\
\hline \multirow{2}{*}{$\begin{array}{l}\text { Joensuu et al. } \\
2010\end{array}$} & Doc & 115 & Doc $100 \mathrm{mg} / \mathrm{m}^{2}$ i.v.d $\mathrm{d}_{1}$, q21d \\
\hline & Doc/Gem & 122 & Doc $100 \mathrm{mg} / \mathrm{m}^{2}$ i.v.d ${ }_{1}$, q21d, Gem $1000 \mathrm{mg} / \mathrm{m}^{2}$ i.v. $\mathrm{d}_{1,8}$, $21 \mathrm{~d}$ \\
\hline \multirow{2}{*}{$\begin{array}{l}\text { Martín et al. } \\
2007\end{array}$} & $\mathrm{Gem} / \mathrm{Nvb}$ & 125 & Nvb $30 \mathrm{mg} / \mathrm{m}^{2}$ i.v. $\mathrm{d}_{1,8}$, Gem $1200 \mathrm{mg} / \mathrm{m}^{2}$ i.v. $\mathrm{d}_{1,8}, \mathrm{q} 21 \mathrm{~d}$ \\
\hline & $\mathrm{Nvb}$ & 126 & $\mathrm{Nvb} 30 \mathrm{mg} / \mathrm{m}^{2}$ i.v. $\mathrm{d}_{1,8}, \mathrm{q} 21 \mathrm{~d}$ \\
\hline \multirow{2}{*}{$\begin{array}{l}\text { Nielsen et al. } \\
2011\end{array}$} & Gem/Doc & 170 & Gem $1200 \mathrm{mg} / \mathrm{m}^{2}$ i.v. $\mathrm{d}_{1,8}$, Doc $75 \mathrm{mg} / \mathrm{m}^{2}$ i.v. $\mathrm{d}_{8}$, q21d \\
\hline & Doc & 167 & Doc $100 \mathrm{mg} / \mathrm{m}^{2}$ i.v. $\mathrm{d}_{1}$, q21d \\
\hline \multirow[t]{2}{*}{ Pallis et al. 2011} & $\mathrm{Gem} / \mathrm{Nvb}$ & 74 & Nvb $25 \mathrm{mg} / \mathrm{m}^{2}$ i.v. $\mathrm{d}_{1,15}$, Gem $1000 \mathrm{mg} / \mathrm{m}^{2}$ i.v. $\mathrm{d}_{1,15}, \mathrm{q} 28 \mathrm{~d}$ for 6 cycles \\
\hline & Cap & 74 & Cap $1250 \mathrm{mg} / \mathrm{m}^{2}$ bid, $\mathrm{d}_{1-14}, \mathrm{q} 21 \mathrm{~d}$ for 6 cycles \\
\hline \multirow{2}{*}{$\begin{array}{l}\text { Papadimitriou } \\
\text { et al. } 2009\end{array}$} & Doc/Gem & 41 & Doc $35 \mathrm{mg} / \mathrm{m}^{2}$ i.v. $\mathrm{d}_{1,8,15}$, Gem $600 \mathrm{mg} / \mathrm{m}^{2}$ i.v. $\mathrm{d}_{1,8,15}$, q3w for 6 cycles \\
\hline & Doc & 34 & Doc $40 \mathrm{mg} / \mathrm{m}^{2}$ i.v. $\mathrm{d}_{1,8,15}, \mathrm{q} 3 \mathrm{w}$ for 6 cycles \\
\hline \multirow[t]{2}{*}{ Park et al. 2013} & $\begin{array}{l}\mathrm{Gem} / \mathrm{Pac} \longrightarrow \\
\mathrm{Gem} / \mathrm{Pac}\end{array}$ & 116 & Gem $1250 \mathrm{mg} / \mathrm{m}^{2}$ i.v. $\mathrm{d}_{1,8}$, Pac $175 \mathrm{mg} / \mathrm{m}^{2}$ i.v. $\mathrm{d}_{1}$, q21d \\
\hline & $\begin{array}{l}\mathrm{Gem} / \mathrm{Pac} \rightarrow \\
\text { Obersavation }\end{array}$ & 115 & / \\
\hline \multirow[t]{3}{*}{ Swain et al. 2013} & Doc/Dox/Cyc & 1630 & Dox $50 \mathrm{mg} / \mathrm{m}^{2}$ i.v., Cyc $500 \mathrm{mg} / \mathrm{m}^{2}$ i.v., Doc $75 \mathrm{mg} / \mathrm{m}^{2}$ i.v. q3w \\
\hline & $\begin{array}{l}\mathrm{Dox} / \mathrm{Cyc} \rightarrow \\
\mathrm{Pac}\end{array}$ & 1634 & $\begin{array}{c}\text { Dox } 60 \mathrm{mg} / \mathrm{m}^{2} \text { i.v., Cyc } 600 \mathrm{mg} / \mathrm{m}^{2} \text { i.v., } \mathrm{q} 2 \mathrm{w} \text { for } 4 \text { cycles } \rightarrow \text { Pac } 175 \\
\text { mg/m² i.v. } \mathrm{q} 2 \mathrm{w} \text { for } 4 \text { cycles }\end{array}$ \\
\hline & $\begin{array}{l}\mathrm{Dox} / \mathrm{Cyc} \rightarrow \\
\mathrm{Gem} / \mathrm{Pac}\end{array}$ & 1630 & $\begin{array}{c}\text { Dox } 60 \text { mg/m² i.v., Cyc } 600 \mathrm{mg} / \mathrm{m}^{2} \text { i.v., q2w for } 4 \text { cycles } \rightarrow \text { Pac } 175 \\
\text { mg/m² i.v., Gem } 2000 \text { mg/m² i.v.q2w for } 4 \text { cycles }\end{array}$ \\
\hline \multirow[t]{2}{*}{ Vici et al. 2011} & Gem/Doc & 36 & Gem $1000 \mathrm{mg} / \mathrm{m}^{2}$ i.v. $\mathrm{d}_{1,8}$, Doc $75 \mathrm{mg} / \mathrm{m}^{2}$ i.v. $\mathrm{d}_{1}$, q21d for 8 cycles \\
\hline & Cap/Doc & 36 & Cap $1250 \mathrm{mg} / \mathrm{m}^{2}$ bid $\mathrm{d}_{1-14}$, Doc $75 \mathrm{mg} / \mathrm{m}^{2}$ i.v. $\mathrm{d}_{1}$, q21d for 8 cycles \\
\hline \multirow[t]{2}{*}{$\begin{array}{l}\text { Zielinski et al. } \\
2005\end{array}$} & Gem/Epi/Pac & 124 & 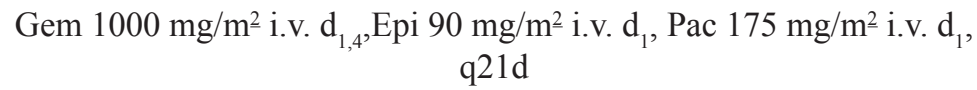 \\
\hline & 5-FU/Epi/Ctx & 135 & 5-FU $500 \mathrm{mg} / \mathrm{m}^{2}$ i.v. $\mathrm{d}_{1}$, Epi $90 \mathrm{mg} / \mathrm{m}^{2}$ i.v. $\mathrm{d}_{1}$, Ctx $500 \mathrm{mg} / \mathrm{m}^{2} \mathrm{~d}_{1}, \mathrm{q} 21 \mathrm{~d}$ \\
\hline
\end{tabular}

Abbreviation: $\mathrm{Beva}=$ bevacizumab, Cap $=$ capecitabine, $\mathrm{Cbp}=$ carboplatin, $\mathrm{Cyc}=$ cyclophosphamide, Doc $=$ docetaxel, Dox $=$ doxorubicin, Epi = epirubicin, Gem = gemcitabine, Lap = lapatinib, Nvb = vinorelbine, Pac $=$ paclitaxel, Pem $=$ pemetrexed, 5-Fu $=5$-fluorouracil. 
that patients receiving combination regimens containing gemcitabine had a significant better ORR (risk ratio $(R R)=1.16,95 \%$ CI 1.03 to 1.30 ) (Figure 2C).

\section{Toxicity}

We carefully reviewed all the included studies in our analysis, and found that these studies included over 50 different ADEs. Among them, we provided nine most common ADEs and compared the incidence of grade 3 or 4 ADEs between patients receiving chemotherapy regimens with or without gemcitabine.

It was found that patients receiving combination regimens containing gemcitabine were more likely to have a higher incidence of neutropenia $(\mathrm{RR}=1.33,95 \%$ CI 1.25 to 1.42 ) (Figure $3 \mathrm{~A})$, thrombocytopenia $(\mathrm{RR}=$ $6.54,95 \%$ CI 4.10 to 10.45$)$ (Figure $3 \mathrm{~B})$, anemia ( $R R=$ $2.37,95 \%$ CI 1.59 to 3.52 ) (Figure $3 \mathrm{C}$ ), and an increased level of serum alanine aminotransferase (ALT) (RR $=2.22$, 95\% CI 1.34 to 3.69) (Figure 3D). In addition, patients receiving combination regimens containing gemcitabine were more likely to have less severe diarrhea $(\mathrm{RR}=0.64,95 \% \mathrm{CI} 0.49$ to 0.83 ) (Figure $3 \mathrm{~F})$, alopecia $(\mathrm{RR}=0.86,95 \% \mathrm{CI} 0.74$ to 0.99$)$ (Figure $3 \mathrm{H})$. The incidence of nausea/vomiting $(\mathrm{RR}=0.87,95 \% \mathrm{CI}$ 0.68 to 1.11 ) (Figure $3 \mathrm{E})$, fatigue $(\mathrm{RR}=1.15,95 \% \mathrm{CI}$ 0.99 to 1.34 ) (Figure $3 \mathrm{G})$, and neuropathy $(\mathrm{RR}=1.22$, $95 \%$ CI 0.99 to 1.50 ) was similar between 2 groups (Figure 3I).

\section{Quality of life}

Altogether 3 studies [16, 17, 27] reported the outcome of QoL in ABC patients. Amadori et al. [16] and Fountzilas et al. [27], reported that there was no significant difference in QoL between the treatment groups, while Brufsky et al. [17] found that QoL in patients with nongemcitabine chemotherapy was better improved than that in patients with gemcitabine chemotherapy. According to our initial literature research, Moinpour et al. [21] found that QoL comparison study favored the gemcitabine combination therapy.

\section{Subgroup analysis}

\section{Comparision between gemcitabine-containing and non-gemcitabine-containing regimens in first-line setting}

Altogether 10 studies used gemcitabine as the firstline treatment $[12-15,17,18,27,28,32,33]$ and the other 5 studies $[19,26,29-31]$ used gemcitabine as the second-line chemotherapy. In studies using gemcitabine as first-line treatment, patients with gemcitabine-containing regimens had a significantly longer OS $(\mathrm{HR}=1.19,95 \%$ CI 1.07 to 1.32 ) (Figure 4A), PFS (HR $=1.17,95 \% \mathrm{CI}$ 1.08 to 1.27 ) (Figure $4 \mathrm{C})$ and a higher $\mathrm{ORR}(\mathrm{RR}=1.16$, 95\% CI 1.02 to 1.32 ) (Figure 4E) than patients with nongemcitabine-containing regimens. However, the trend is not seen in studies using gemcitabine as post first-line treatment $(\mathrm{OS}: \mathrm{HR}=0.98,95 \%$ CI 0.81 to 1.18 , Figure 4B; PFS: $\mathrm{HR}=1.04,95 \% \mathrm{CI} 0.94$ to 1.16 , Figure 4D; ORR: $R R=1.15,95 \%$ CI 0.92 to 1.45 , Figure $4 \mathrm{~F}$ ).

\section{Comparison of the efficacy between additional gemcitabine and gemcitabine replacement regimens}

Of the 15 studies in our analysis, 7 studies used additional gemcitabine chemotherapy $[12,15,17,18$, 29-31], and the other 8 used gemcitabine replacement regimens. In studies using additional gemcitabine chemotherapy, a significantly longer OS $(\mathrm{HR}=1.17$, $95 \%$ CI 1.06 to 1.30 ) (Figure 5A), PFS ( $\mathrm{HR}=1.20$, 95\% CI 1.11 to 1.30 ) (Figure 5C) and a higher ORR $(\mathrm{RR}=1.23,95 \%$ CI 1.06 to 1.42 ) (Figure 5E) were found, while the difference in $\mathrm{OS}(\mathrm{HR}=1.12,95 \% \mathrm{CI} 0.97$ to 1.28$)$ (Figure 5B), PFS (HR $=1.01,95 \%$ CI 0.91 to 1.12 ) (Figure 5D) and ORR (RR $=1.06,95 \% \mathrm{CI} 0.89$ to 1.27 ) (Figure 5F) was similar in patients receiving gemcitabine replacement regimens.
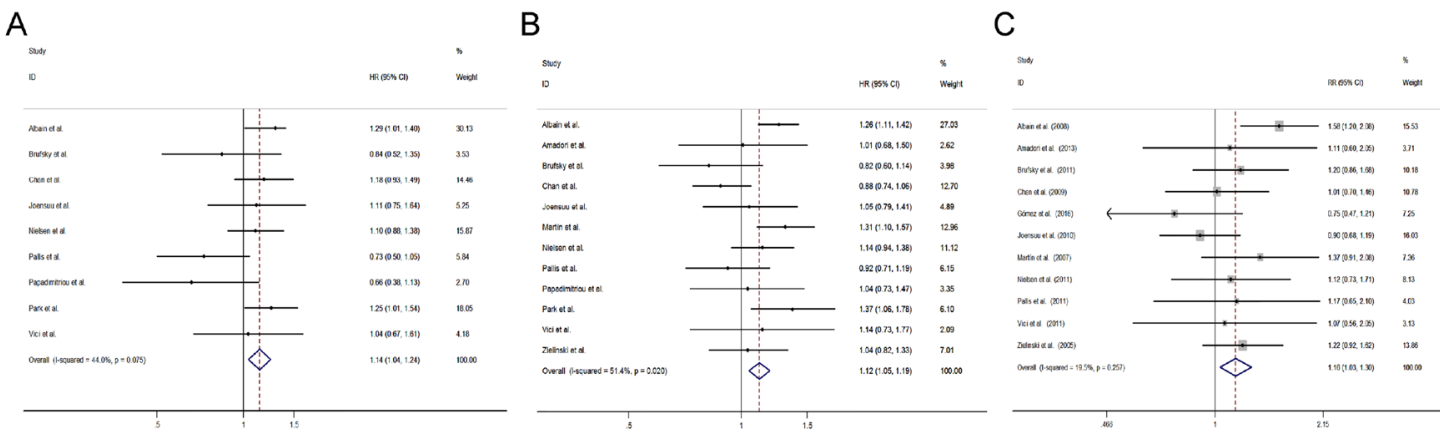

Figure 2: Comparisons of primary outcomes between gemcitabine-containing and non-gemcitabine-containing regimens. (A) Overall survival, (B) Progression free survival, (C) Objective tumor response rate. 


\section{Efficacy of gemcitabine and taxanes combination therapy}

Nine $[12,13,15,17,18,26,31-33]$ of the 15 included studies used gemcitabine combined taxanes chemotherapy regimen. Pooled results of studies combining gemcitabine and taxanes showed that patients using the gemcitabine-containing regimens had a better OS $(\mathrm{HR}=1.17,95 \% \mathrm{CI} 1.06$ to 1.28$)$ (Figure 6A), PFS $(\mathrm{HR}=1.12,95 \% \mathrm{CI} 1.04$ to 1.20$)$ (Figure 6C) and ORR $(\mathrm{RR}=1.17,95 \%$ CI 1.01 to 1.35$)$ (Figure $6 \mathrm{E}$ ) than patients with non-gemcitabine-containing regimens. However, there was no significant difference in $\mathrm{OS}(\mathrm{HR}=0.78$, $95 \%$ CI 0.60 to 1.26 ) (Figure $6 \mathrm{~B})$, PFS (HR $=1.12,95 \%$ CI 0.99 to 1.26$)$ (Figure 6D) and ORR $(R R=1.14,95 \%$ CI 0.94 to 1.36) (Figure 6F) between studies using nongemcitabine-taxanes-combination therapy.
During the initial literature searching process, we found that there was a meta-analysis comparing the safety and efficacy of gemcitabine and taxanes combination therapy in ABC patients [34]. They found that ORR and time to progression were superior for gemcitabine/ taxanes-treated patients (ORR, odd ratio $=1.28,95 \% \mathrm{CI}$ 1.07 to 1.53 ; time to progression, $\mathrm{HR}=0.80,95 \% \mathrm{CI} 0.71$ to 0.89$)$. And gemcitabine/ taxanes-based combination significantly improved OS in the first-line subgroup $(\mathrm{HR}=0.84 ; 95 \%$ CI 0.71 to 0.99$)$.

\section{Sensitivity analysis}

To test whether our meta-analysis results were skewed because of the study with high risk of bias, we repeated the analyses after excluding the study [14] (the initial quality assessment of included studies is shown in Supplementary
A

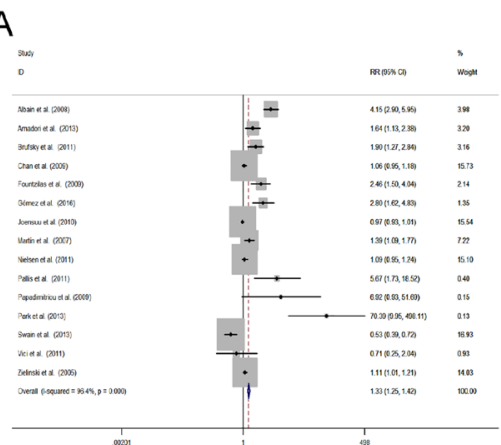

D
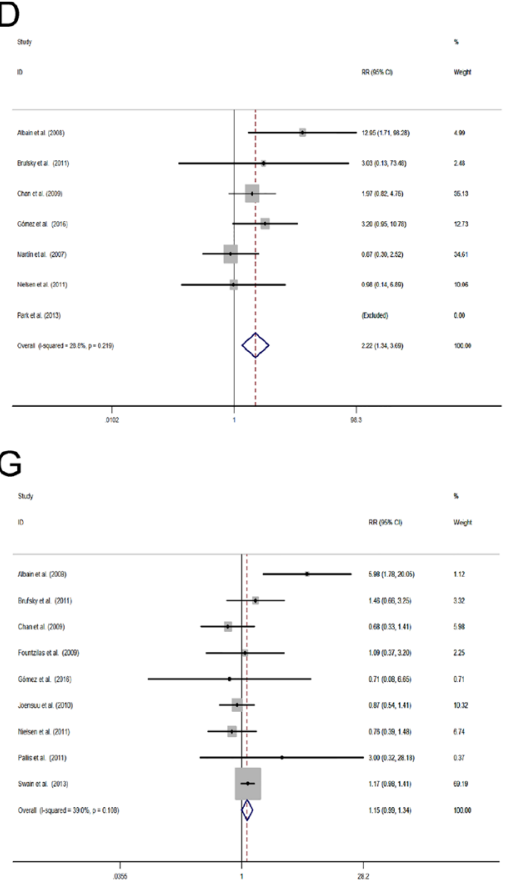

B

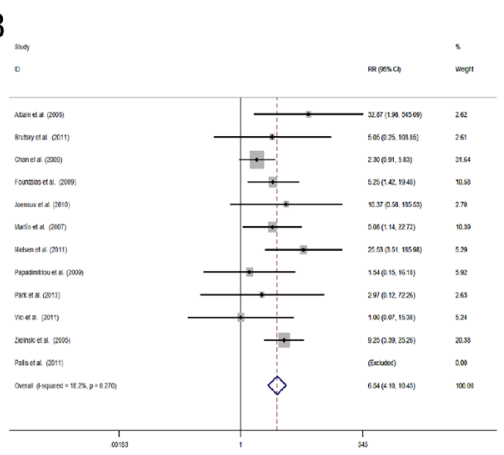

E
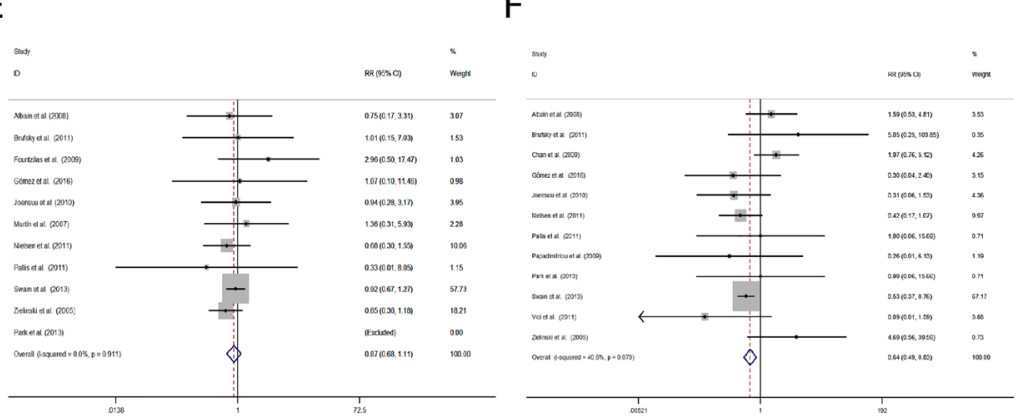

$\mathrm{H}$

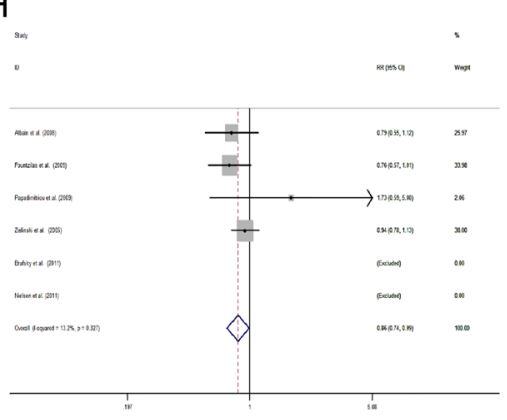

F

C

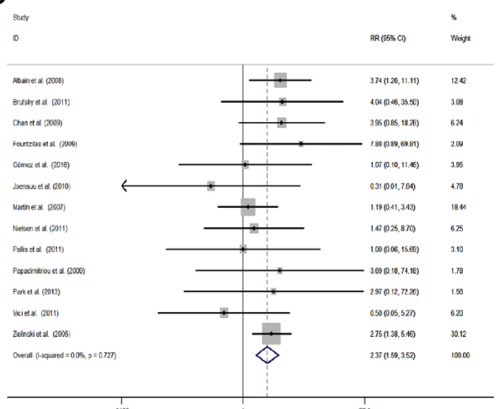

Figure 3: Comparisons of toxicity between gemcitabine-containing and non-gemcitabine-containing regimens. (A) Neutropenia, (B) Thrombocytopenia, (C) Anemia, (D) Aalanine aminotransferase, (E) Nausea/vomiting, (F) Diarrhea, (G) Fatigue, (H) Alopecia, (I) Neuropathy. 
Table 1). The results for PFS (HR $=1.12,95 \% \mathrm{CI}$ 1.05 to 1.20 ) (Supplementary Figure 1 ) and $\mathrm{ORR}(\mathrm{RR}=1.15$, 95\% CI 1.02 to 1.30) (Supplementary Figure 2) were similar to those obtained when including the study with high risk of bias, suggesting that our meta-analysis is reliable.

Moreover, we also switched the fix- and randommodel to test the sensitivity of the outcome, and found that recalculated ORR $(\mathrm{RR}=1.14,95 \% \mathrm{CI} 1.00$ to 1.30 , random model) (Supplementary Figure 3 ) was similar to the previous ORR $(\mathrm{RR}=1.16,95 \%$ CI 1.03 to 1.30 , fix model $)$.

\section{Publication bias}

Funnel plots were generated and analyzed using Egger's tests in order to assess the risk of publication bias in all included studies. The funnel plots for ORR appeared to be symmetrical, suggesting the absence of bias. This was corroborated by Egger's test $(t=-0.77, P=0.459)$ (Supplementary Figure 4).

\section{DISCUSSION}

The treatment of $\mathrm{ABC}$ is a clinical challenge because of its propensity for late presentation with inoperable disease, aggressive tumor biology, and resistance to chemotherapy [35-37]. Taxane/anthracycline-based chemotherapy is the treatment of choice in most cancer centers and countries for the treatment of $\mathrm{ABC}$, and a wide variety of single agents or combination therapies have been investigate for patients previously treated with both a taxane and an anthracycline [38]. As an outstanding anti-tumor agent, gemcitabine has been evaluated in many randomized controlled trials for $\mathrm{ABC}$, showing a favorable clinical outcome [25, 29]. However, whether gemcitabinecontaining chemotherapy is better than non-gemcitabinecontaining treatment still lacks adequate evidence. To compare the efficacy and tolerability of gemcitabinecontaining chemotherapy in the treatment of $\mathrm{ABC}$ patients with sufficient statistical power, we performed this systematic review to overcome the statistical limitations (for instance, low case load) of the individual trials by comparing the treatment efficacy, safety profile and survival benefit between various subgroups.

This systematic review revealed that gemcitabinecontaining chemotherapy was associated with significantly enhanced OS $(\mathrm{HR}=1.14,95 \% \mathrm{CI} 1.04$ to 1.24$)$, PFS $(\mathrm{HR}=1.12,95 \%$ CI 1.05 to 1.19$)$, and ORR $(\mathrm{RR}=1.16$, $95 \%$ CI 1.03 to 1.30 ) over non-gemcitabine-containing chemotherapy. Our initial review revealed another metaanalysis that also conducted a similar comparison [39]. Interestingly, they reported that OS, PFS and ORR were similar between ABC patients with or without gemcitabine-containing regimens. In their study, 9 trials including 2651 patients $[12,14,15,17,18,20,26,29,30]$ were eligible for the meta-analysis. Compared with their
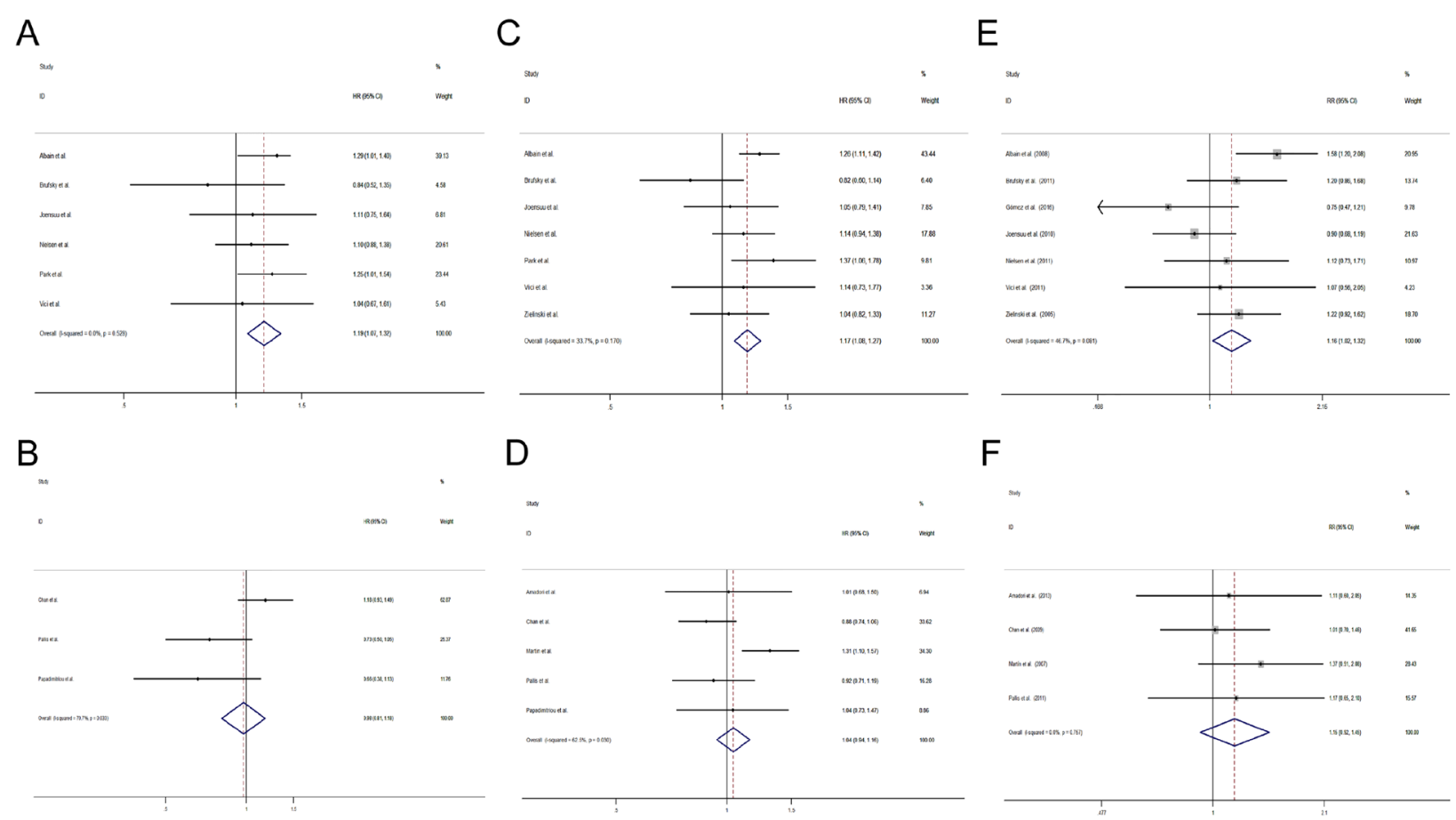

D

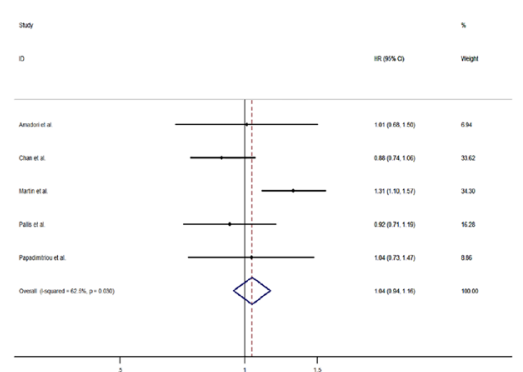

$\mathrm{F}$

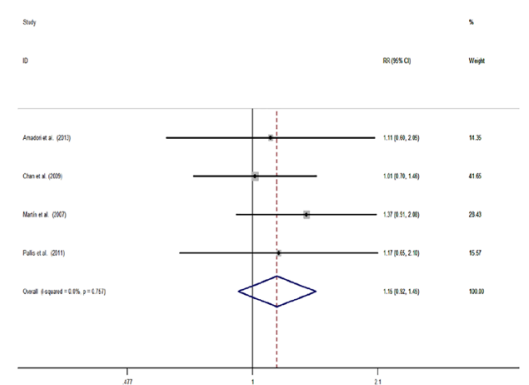

Figure 4: Comparisons of primary outcomes between studies using gemcitabine-containing regimens as first-line and second-line treatment. (A) Overall survival (first-line), (B) Overall survival (second-line) (C) Progression free survival (first-line), (D) Progression free survival (second-line), (E) Objective tumor response rate (first-line), (F) Objective tumor response rate (second-line). 

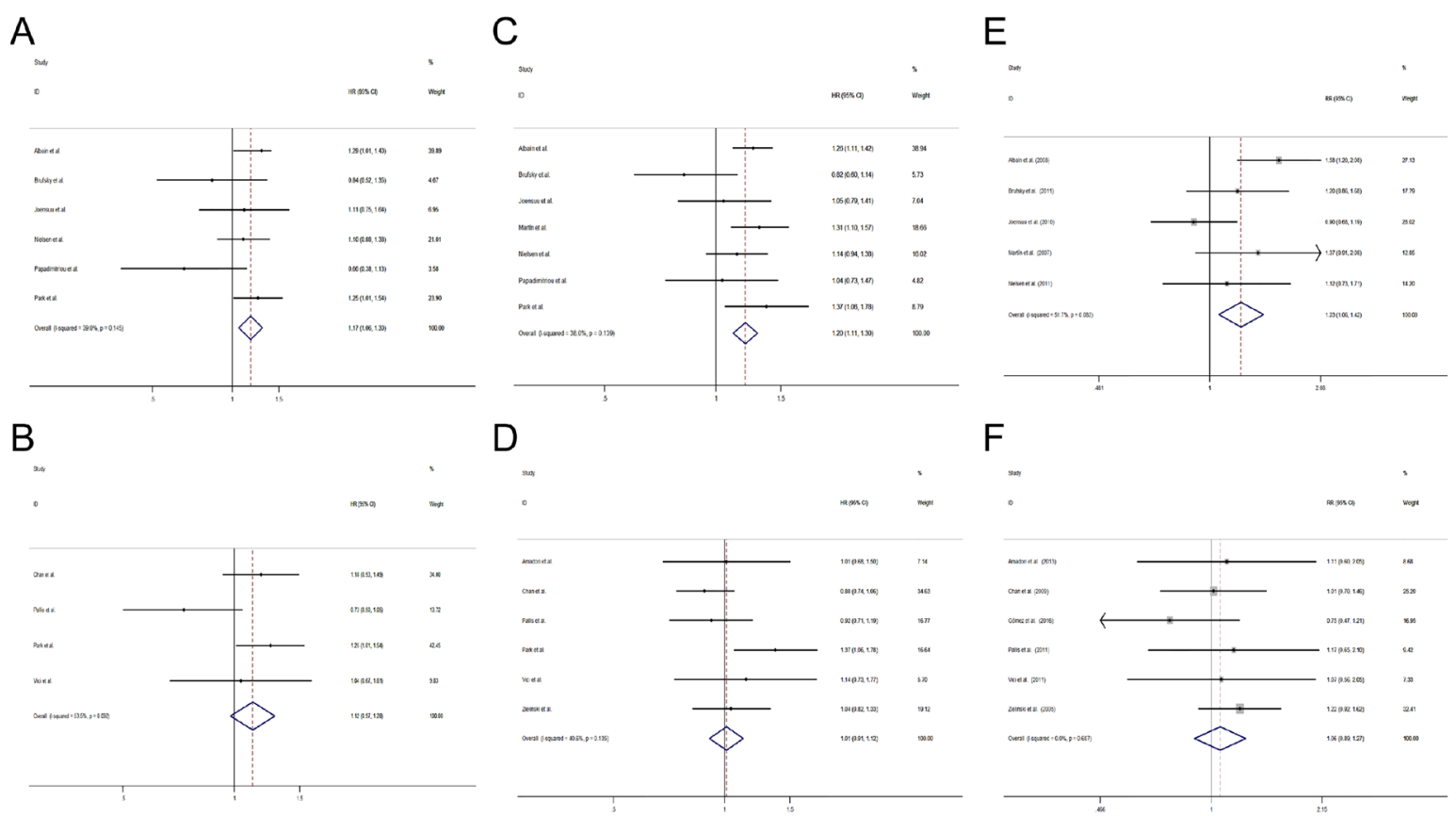

Figure 5: Comparisons of primary outcomes between studies using additional gemcitabine and studies using gemcitabine as replacement chemotherapy. (A) Overall survival (additional gemcitabine chemotherapy), (B) Overall survival (gemcitabine replacement chemotherapy) (C) Progression free survival (additional gemcitabine chemotherapy), (D) Progression free survival (gemcitabine replacement chemotherapy), (E) Objective tumor response rate (additional gemcitabine chemotherapy), (F) Objective tumor response rate (gemcitabine replacement chemotherapy).

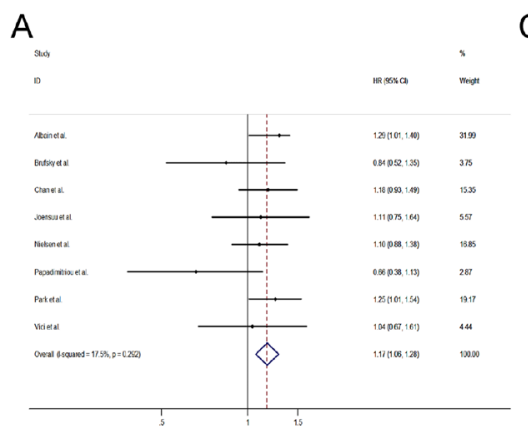

B

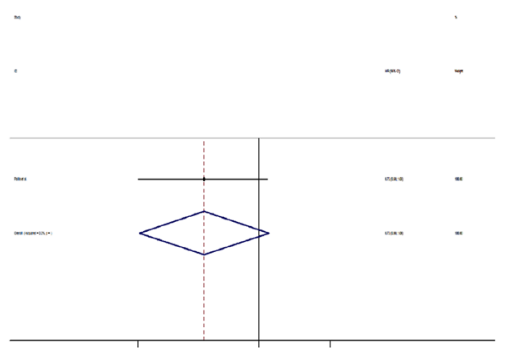

C

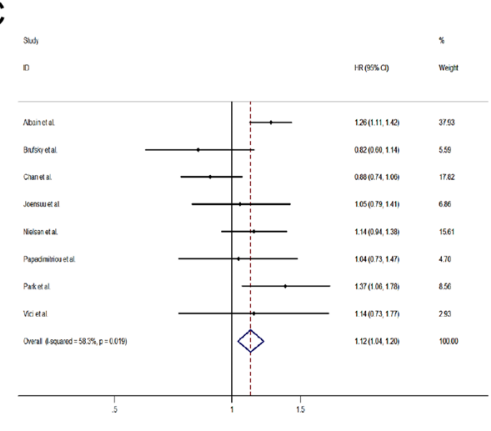

D

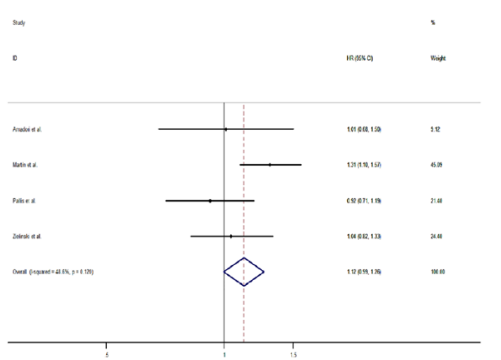

$\mathrm{F}$
E
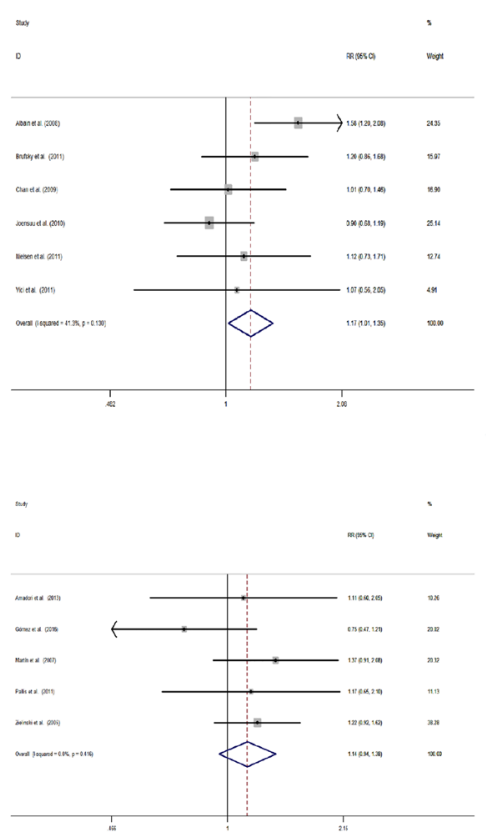

Figure 6: Comparisons of primary outcomes between studies with gemcitabine- taxanes-based regimens and studies with non-gemcitabine-taxanes-based regimens. (A) Overall survival (gemcitabine-taxanes-based regimens), (B) Overall survival (non-gemcitabine-taxanes-based regimens) (C) Progression free survival (gemcitabine-taxanes-based regimens), (D) Progression free survival (non-gemcitabine-taxanes-based regimens), (E) Objective tumor response rate (gemcitabine-taxanes-based regimens), (F) Objective tumor response rate (non-gemcitabine-taxanes-based regimens). 
inclusion, we additionally include 7 studies, and excluded Feher et al.'s study [20] because they used monotherapy of gemcitabine in the experimental group and only included postmenopausal women aged 60 years or older, which we were afraid may produce significant selection bias in our analysis. According to Brufsky et al.'s study [17], gemcitabine-containing chemotherapy was associated with significantly improved ORR as compared with nongemcitabine-containing chemotherapy in patients younger than 65 years. Nevertheless, the trend was not significant in patients older than 65 years, indicating that age may affect the survival outcome. Included patients with older age were often postmenopausal women, and estrogen deficiency may affect the efficacy of chemotherapy [40]. Li et al. [39] found a significant bias in Feher et al.'s study and therefore excluded it from their meta-analysis. Interestingly, they also found that the insignificant difference between 2 arms turned significant. The dramatic change demonstrated a selection bias and inconvincible results in Li et al.'s [39] study, and we excluded Feher et al.'s study and conducted a new systematic review in order to provide more authentic results.

Severe toxicity is an important concern when combination chemotherapy is considered, especially in elderly patients and those who have poor PS score. Thus, toxicity and QoL have become equally important in assessing the therapeutic efficacy and determining the course of palliative chemotherapy. Toxicity is a major concern with gemcitabine. It was found in our study that additional use of gemcitabine increased the incidence of grade 3-4 hematopoietic system toxicity including neutropenia, thrombocytopenia and anemia, and increased the serum level of ALT [41]. Although gemcitabine combining regimens significantly increased the incidence of grade 3-4 hematopoietic and liver function impairment, few serious AEDs were reported. According to Zielinski et al. [14] thrombocytopenia did not constitute a clinical problem in patients treated with gemcitabine-combining regimens, because no bleeding episodes was reported. The rate of grade 3 and 4 myelosuppressive activity in patients with second-line therapy was lower as compared with first-line treatment studies with similar toxicity profiles, which could be attributed to the difference in the total durations of drug exposure in the previous treatment [42]. Furthermore, grade 3 or 4 hematologic toxicities were not commonly associated with clinical events such as transfusions [20]. Viewing the ADEs by age, some differences in toxicities would be noted. In patients with elder age, the severity and the incidence may increase [20]. Thus the toxic effects of the gemcitabine combination regimens are manageable when they are used with caution in elderly patients. QoL difference between patients with or without gemcitabine containing chemotherapy varies greatly, and further investigation is required before a convincing conclusion can be drawn.
Subgroup analysis of first- or second-line therapy revealed that gemcitabine containing chemotherapy was beneficial to $\mathrm{ABC}$ patients when it was used as the first-line therapy. Interestingly, gemcitabine has shown a modest activity as a single agent in ABC, especially when the drug was used as second-line or third-line treatment [43]. The satisfied survival benefit may be attributed to the included populations. Gemcitabine containing chemotherapy was used as the second-line therapy in these patients, mainly because of drug resistance to the previous first-line therapy or disease progression. Indeed, any therapy may not be as effective as expected in these patients. Thus, the result of survival benefits of gemcitabine containing regimens in first-line treatment would help clinical doctors make rational and efficacious chemotherapeutic protocols. According to Carrick et al. [44], combination regimens had a higher response rate than single-drug regimens, but sequential use of a single agent was associated with better QoL and similar or nearly similar survival, which may be the reason why mono-chemotherapy has widely been accepted as a better approach to breast cancer management. Nevertheless, the above-mentioned results were not based on gemcitabine containing regimens. Subgroup analysis in our study showed that gemcitabine, when used as an additional agent in chemo-regimens, brought significant survival and tumor response benefits as compared with gemcitabine replacement chemotherapy. In addition, a large multicenter trial reported that the combination was more effective than single-agent paclitaxel in terms of the response rate, time-to-disease progression, and OS [12] suggesting that gemcitabine combining regimens could bring better survival outcomes and tumor response. In our study, gemcitabine containing regimens increased the incidence of hematologic toxicity, though it was manageable.

In addition, QoL comparison in some studies favored the gemcitabine combination therapy. However, we did not compare the difference in survival and tumor response between the gemcitabine combination regimen and the single gemcitabine regimen. Further study is required to compare the efficacy of single gemcitabine in $\mathrm{ABC}$ patients. It was found in our study that gemcitabine combined with taxanes was the most commonly used regimen. Currently, taxanes are usually introduced early in the treatment of ABC patients' treatment. In addition, taxanes are commonly used in patients with no or minimal prior anthracycline exposure and/or in combination with anthracyclines and gemcitabin [45]. Gemcitabine combined with taxanes doublet is a well-tolerated choice for $\mathrm{ABC}$ women after adjuvant anthracycline therapy or in whom the cardiotoxic effects of anthracyclines preclude its use [12]. Despite the manageable toxicity, the analysis of the global QoL end point from the QoL companion study still favored the regimens containing gemcitabine and taxanes [21]. A recently published meta-analysis compared the efficacy and toxicity in patients receiving chemotherapy with or without 
gemcitabine-taxanes-based regimens [34], and found that ORR and time to progression were superior to gemcitabine and taxanes treated patients, which is consistent with our subgroup analysis. They also found that gemcitabinetaxanes-based combination also significantly improved $\mathrm{OS}$ in the first-line subgroup $(\mathrm{HR}=0.84 ; 95 \% \mathrm{CI} 0.71$ to 0.99). All evidence suggests that gemcitabine-taxanes-based chemotherapy may be a feasible regimen for $\mathrm{ABC}$ patients.

The biggest limitation of this systematic review is the heterogeneity of the included studies. The study designs and study inclusion criteria are totally different between different studies, and the pooled results might have biases. In order to make our results more convincible, we conducted sensitivity analysis. By excluding the study with high risk of bias, the final results for PFS and ORR are similar to previous results, suggesting that our metaanalyses are reliable. In addition, we also switched the fixand random-model to test the sensitivity of the outcome, and found that recalculated ORR $(\mathrm{RR}=1.14,95 \% \mathrm{CI}$ 1.00 to 1.30 , random model) were similar to previous ORR $(\mathrm{RR}=1.16,95 \% \mathrm{CI} 1.03$ to 1.30 , fix model). Additionally, funnel plots of publication bias for ORR appear to be symmetrical, suggesting the absence of bias. All above evidence shows that the results in our study are convincible.

In conclusion, a gemcitabine-based regimen possesses meaningful anti-tumor activity in the treatment of $\mathrm{ABC}$, repeatedly demonstrating outcomes favored to non-gemcitabine-containing agents, especially for first-line treatment in $\mathrm{ABC}$ patients. Gemcitabine-based regimens could serve as promising regimens, although increased hematologic toxicity should be considered.

\section{METHODS}

This meta-analysis was conducted according to PRISMA guidelines (Checklist S1).

\section{Literature search strategy}

Systematic searches of the following electronic databases were conducted through January 2017 without language restrictions: MEDLINE, EMBASE, the Cochrane Library, and the Chinese National Knowledge Infrastructure. We also searched five primary clinical trial registries recognized by the WHO International Clinical Trial Registry Platform: Australia and New Zealand Clinical Trial Registry (www.anzctr.org.au/), Chinese Clinical Trial Register (www. chictr.org.cn), ISRCTN (www.controlled-trials.com/isrctn/), U.S. National Institutes of Health Clinical Trials Database (www.clinicaltrials.gov/), and Clinical Trials Registry-India (www.ctri.in:8080/Clinicaltrials/index.jsp) [46, 47]. Eligible studies were identified using any of the following index words: "gemcitabine," "chemotherapy," and "breast cancer". Relevant reviews and meta-analyses comparing combination regimens with or without gemcitabine for $\mathrm{ABC}$ were examined manually to identify additional eligible studies.

\section{Inclusion criteria}

Studies included in our analysis had to satisfy the following criteria: (1) randomized clinical trials; (2) trials including a group that received combination regimens containing gemcitabine and a group that received chemotherapy regimens without gemcitabine; (3) trials reporting data on OS or PFS as the clinical outcome; (4) trials including $\mathrm{ABC}$ with histologically confirmed invasive breast cancer and measurable or non-measurable distant metastases as confirmed by histology and/or radiology); (5) trials reporting sufficient data to allow calculation of the RR or HR with $95 \% \mathrm{CI}$.

\section{Types of outcome measures}

Primary outcomes evaluated in the meta-analysis were OS, PFS and tumor response. Tumor response was classified according to the Modified Response Evaluation Criteria in Solid Tumors (mRECIST) [48, 49]. Tumor responses were classified as complete response, partial response, stable disease and progressive disease. The ORR was calculated by summing the complete response rate and partial response rate. Secondary outcomes were toxicity and QoL. Toxicity was graded according to the National Cancer Institute Common Toxicity Criteria (Version 3.0). We only included grade 3 or 4 common ADEs into our analysis.

\section{Data extraction}

The following data were extracted independently by two reviewers (Z.B.X and Y.F.Z): the first author's name, year of publication, tumor characteristics, number of patients, and line of therapy. For each group, the intervention, number of patients, ORR, duration of response, OS, PFS and toxicity were also collected. Any disagreements about study eligibility or extracted data were arbitrated by a third reviewer (D.L.F).

\section{Quality assessment}

Two reviewers (Z.B.X and Y.F.Z) independently evaluated all the included trials and independently assessed the risk of bias for each study using criteria specified by Cochrane Collaboration Back Review Group [50].

\section{Statistical analysis}

All statistical calculations were performed using Stata 12.0 (Stata Corp, College Station, TX, USA). Mantel-Haenszel RRs with corresponding 95\% CIs were calculated for tumor response. Survival data (OS and PFS) were extracted from survival curves [51] and HRs with 
95\% CIs were calculated. The meta-analysis was carried out on an 'intention-to-treat' basis. Heterogeneity was assessed by calculating $I^{2}$. When $I^{2}$ was less than $50 \%$, a fixed-effects model was used; when $I^{2}$ was more than $50 \%$, a random-effects model was used. Homogeneity between trials was assessed using the $\chi^{2}$ test with the significance threshold set at $P>0.1$. To evaluate the robustness of the meta-analysis results, we repeated all meta-analyses using the other type of model (fixed- or random-effects); if both models gave the same meta-analysis results, we judged the result to be reliable. Publication bias was assessed using Egger's test and funnel plots $[52,53]$ in Stata 12.0.

\section{Abbreviations}

ABC: advanced breast cancer; ADE: adverse event; $\mathrm{CI}$ : confidence interval, HR: hazard ratio; ORR: objective response rate; OS: overall survival; PFS: progression free survival; QoL: quality of life; RR: risk ratio.

\section{Author contributions}

Conception and design: Zhi-Bo Xie, Yi-Fan Zhang, and De-Liang Fu. Provision of study materials or patients: Zhi-Bo Xie, and Chen Jin. Collection and assembly of data: Zhi-Bo Xie, De-Liang Fu. Data analysis and interpretation: Zhi-Bo Xie, Yi-Fan Zhang, and De-Liang Fu. Manuscript writing: Zhi-Bo Xie, Yi-Fan Zhang, and De-Liang Fu. Final approval of the manuscript: All authors.

\section{ACKNOWLEDGMENTS}

We thank Pro. Shunxing Zhang for language editing.

\section{CONFLICTS OF INTEREST}

The authors disclose no conflicts of interest.

\section{FUNDING}

This work was supported by grants from the National Natural Science Foundation of China (No. 81472221) and Clinical key projects of the National Health and Family Planning (Oncology 2013-2015).

\section{REFERENCES}

1. Torre LA, Bray F, Siegel RL, Ferlay J, Lortet-Tieulent J, Jemal A. Global cancer statistics, 2012. CA Cancer J Clin. 2015; 65:87-108. https://doi.org/10.3322/caac.21262.

2. O'Shaughnessy J, Miles D, Vukelja S, Moiseyenko V, Ayoub JP, Cervantes G, Fumoleau P, Jones S, Lui WY, Mauriac L, Twelves C, Van Hazel G, Verma S, et al. Superior survival with capecitabine plus docetaxel combination therapy in anthracycline-pretreated patients with advanced breast cancer: phase III trial results. J Clin Oncol. 2002; 20:2812-23.

3. Hortobagyi GN, de la Garza Salazar J, Pritchard K, Amadori D, Haidinger R, Hudis CA, Khaled H, Liu MC, Martin M, Namer M, O'Shaughnessy JA, Shen ZZ, Albain KS, et al. The global breast cancer burden: variations in epidemiology and survival. Clin Breast Cancer. 2005; 6:391-401.

4. O'Shaughnessy J. Extending survival with chemotherapy in metastatic breast cancer. Oncologist. 2005; 10 Suppl 3: 20-9. https://doi.org/10.1634/theoncologist.10-90003-20.

5. Amar S, Roy V, Perez EA. Treatment of metastatic breast cancer: looking towards the future. Breast Cancer Res Treat. 2009; 114:413-22. https://doi.org/10.1007/ s10549-008-0032-3.

6. Pronzato P, Rondini M. First-line chemotherapy of metastatic breast cancer. Ann Oncol. 2006; 17:v165-8. https://doi.org/10.1093/annonc/mdj974.

7. Chan S, Friedrichs K, Noel D, Pinter T, Van Belle S, Vorobiof D, Duarte R, Gil Gil M, Bodrogi I, Murray E, Yelle L, von Minckwitz G, Korec S, et al. Prospective randomized trial of docetaxel versus doxorubicin in patients with metastatic breast cancer. J Clin Oncol. 1999; 17:2341-54. https://doi.org/10.1200/JCO.1999.17.8.2341.

8. Valero V, Holmes FA, Walters RS, Theriault RL, Esparza L, Fraschini G, Fonseca GA, Bellet RE, Buzdar AU, Hortobagyi GN. Phase II trial of docetaxel: a new, highly effective antineoplastic agent in the management of patients with anthracycline-resistant metastatic breast cancer. J Clin Oncol. 1995; 13:2886-94. https://doi.org/10.1200/ JCO.1995.13.12.2886.

9. Ershler WB. Capecitabine monotherapy: safe and effective treatment for metastatic breast cancer. Oncologist. 2006; 11:325-35. https://doi.org/10.1634/theoncologist.11-4-325.

10. Aapro MS, Harper P, Johnson SA, Vermorken JB. Developments in cytotoxic chemotherapy: advances in treatment utilising vinorelbine. Crit Rev Oncol Hematol. 2001; 40:251-63.

11. Heinemann V. Gemcitabine in metastatic breast cancer. Expert Rev Anticancer Ther. 2005; 5:429-43. https://doi. org/10.1586/14737140.5.3.429.

12. Albain KS, Nag SM, Calderillo-Ruiz G, Jordaan JP, Llombart AC, Pluzanska A, Rolski J, Melemed AS, Reyes-Vidal JM, Sekhon JS, Simms L, O’Shaughnessy J. Gemcitabine plus Paclitaxel versus Paclitaxel monotherapy in patients with metastatic breast cancer and prior anthracycline treatment. J Clin Oncol. 2008; 26:3950-7. https://doi.org/10.1200/JCO.2007.11.9362.

13. Park YH, Jung KH, Im SA, Sohn JH, Ro J, Ahn JH, Kim SB, Nam BH, Oh DY, Han SW, Lee S, Park IH, Lee KS, et al. Phase III, multicenter, randomized trial of maintenance chemotherapy versus observation in patients with metastatic breast cancer after achieving disease control with six cycles of gemcitabine plus paclitaxel as first-line 
chemotherapy: KCSG-BR07-02. J Clin Oncol. 2013; 31:1732-9. https://doi.org/10.1200/JCO.2012.45.2490.

14. Zielinski C, Beslija S, Mrsic-Krmpotic Z, WelnickaJaskiewicz M, Wiltschke C, Kahan Z, Grgic M, Tzekova V, Inbar M, Cervek J, Chernozemsky I, Szanto J, Spanik S, et al. Gemcitabine, epirubicin, and paclitaxel versus fluorouracil, epirubicin, and cyclophosphamide as first-line chemotherapy in metastatic breast cancer: a Central European Cooperative Oncology Group International, multicenter, prospective, randomized phase III trial. J Clin Oncol. 2005; 23:1401-8. https://doi.org/10.1200/JCO.2005.12.106.

15. Nielsen DL, Bjerre KD, Jakobsen EH, Cold S, Stenbygaard L, Sorensen PG, Kamby C, Moller S, Jorgensen CL, Andersson M. Gemcitabine plus docetaxel versus docetaxel in patients with predominantly human epidermal growth factor receptor 2-negative locally advanced or metastatic breast cancer: a randomized, phase III study by the Danish Breast Cancer Cooperative Group. J Clin Oncol. 2011; 29:4748-54. https://doi.org/10.1200/ JCO.2010.33.9507.

16. Amadori D, Carrasco E, Roesel S, Labianca R, Uziely B, Soldatenkova V, Moreau V, Desaiah D, Bauknecht T, Martin M. A randomized phase II non-comparative study of pemetrexedcarboplatin and gemcitabinevinorelbine in anthracycline- and taxane-pretreated advanced breast cancer patients. Int J Oncol. 2013; 42:1778-85. https://doi. org/10.3892/ijo.2013.1869.

17. Brufsky A, Hoelzer K, Beck T, Whorf R, Keaton M, Nadella P, Krill-Jackson E, Kroener J, Middleman E, Frontiera M, Paul D, Panella T, Bromund J, et al. A randomized phase II study of paclitaxel and bevacizumab with and without gemcitabine as first-line treatment for metastatic breast cancer. Clin Breast Cancer. 2011; 11:211-20. https://doi.org/10.1016/j.clbc.2011.03.019.

18. Joensuu H, Sailas L, Alanko T, Sunela K, Huuhtanen R, Utriainen M, Kokko R, Bono P, Wigren T, Pyrhonen S, Turpeenniemi-Hujanen T, Asola R, Leinonen M, et al. Docetaxel versus docetaxel alternating with gemcitabine as treatments of advanced breast cancer: final analysis of a randomised trial. Ann Oncol. 2010; 21:968-73. https://doi. org/10.1093/annonc/mdp397.

19. Rugo HS, Campone M, Amadori D, Aldrighetti D, Conte P, Wardley A, Villanueva C, Melisko M, McHenry MB, Liu D, Lee F, Pivot X. A randomized, phase II, three-arm study of two schedules of ixabepilone or paclitaxel plus bevacizumab as first-line therapy for metastatic breast cancer. Breast Cancer Res Treat. 2013; 139:411-9. https:// doi.org/10.1007/s10549-013-2552-8.

20. Feher O, Vodvarka P, Jassem J, Morack G, Advani SH, Khoo KS, Doval DC, Ermisch S, Roychowdhury D, Miller MA, von Minckwitz G. First-line gemcitabine versus epirubicin in postmenopausal women aged 60 or older with metastatic breast cancer: a multicenter, randomized, phase III study. Ann Oncol. 2005; 16:899-908. https://doi. org/10.1093/annonc/mdi181.

21. Moinpour CM, Donaldson GW, Liepa AM, Melemed AS, O'Shaughnessy J, Albain KS. Evaluating health-related quality-of-life therapeutic effectiveness in a clinical trial with extensive nonignorable missing data and heterogeneous response: results from a phase III randomized trial of gemcitabine plus paclitaxel versus paclitaxel monotherapy in patients with metastatic breast cancer. Qual Life Res. 2012; 21:765-75. https://doi.org/10.1007/s11136-011-9999-z.

22. Park IH, Ro J, Lee KS, Kim SN, Yun YH, Nam BH. Phase II study of gemcitabine in combination with vinorelbine versus gemcitabine followed by vinorelbine for metastatic breast cancer. Invest New Drugs. 2010; 28:659-69. https:// doi.org/10.1007/s10637-009-9285-x.

23. Seidman AD, Brufsky A, Ansari RH, Hart LL, Stein RS, Schwartzberg LS, Stewart JF, Russell CA, Chen SC, Fein LE, De La Cruz Vargas JA, Kim SB, Cavalheiro J, et al. Phase III trial of gemcitabine plus docetaxel versus capecitabine plus docetaxel with planned crossover to the alternate single agent in metastatic breast cancer. Ann Oncol. 2011; 22:1094-101. https://doi.org/10.1093/annonc/mdq578.

24. Seidman AD, Chan S, Wang J, Zhu C, Xu C, Xu B. A pooled analysis of gemcitabine plus docetaxel versus capecitabine plus docetaxel in metastatic breast cancer. Oncologist. 2014; 19:443-52. https://doi.org/10.1634/ theoncologist.2013-0428.

25. Tomova A, Bartsch R, Brodowicz T, Tzekova V, Timcheva C, Wiltschke C, Gerges DA, Pawlega J, Spanik S, Inbar M, Zielinski CC. Concomitant docetaxel plus gemcitabine versus sequential docetaxel followed by gemcitabine in anthracycline-pretreated metastatic or locally recurrent inoperable breast cancer patients: a prospective multicentre trial of the Central European Cooperative Oncology Group (CECOG). Breast Cancer Res Treat. 2010; 119:169-76. https://doi.org/10.1007/s10549-009-0553-4.

26. Chan S, Romieu G, Huober J, Delozier T, TubianaHulin M, Schneeweiss A, Lluch A, Llombart A, du Bois A, Kreienberg R, Mayordomo JI, Anton A, Harrison M, et al. Phase III study of gemcitabine plus docetaxel compared with capecitabine plus docetaxel for anthracyclinepretreated patients with metastatic breast cancer. J Clin Oncol. 2009; 27:1753-60. https://doi.org/10.1200/ JCO.2007.15.8485.

27. Fountzilas G, Dafni U, Dimopoulos MA, Koutras A, Skarlos D, Papakostas P, Gogas H, Bafaloukos D, KalogeraFountzila A, Samantas E, Briasoulis E, Pectasides D, Maniadakis N, et al. A randomized phase III study comparing three anthracycline-free taxane-based regimens, as first-line chemotherapy, in metastatic breast cancer: a Hellenic Cooperative Oncology Group study. Breast Cancer Res Treat. 2009; 115:87-99. https://doi.org/10.1007/ s10549-008-0047-9. 
28. Gomez HL, Neciosup S, Tosello C, Mano M, Bines J, Ismael G, Santi PX, Pinczowski H, Neron Y, Fanelli M, Fein L, Sampaio C, Lerzo G, et al. A Phase II Randomized Study of Lapatinib Combined With Capecitabine, Vinorelbine, or Gemcitabine in Patients With HER2Positive Metastatic Breast Cancer With Progression After a Taxane (Latin American Cooperative Oncology Group 0801 Study). Clin Breast Cancer. 2016; 16:38-44. https:// doi.org/10.1016/j.clbc.2015.10.005.

29. Martin M, Ruiz A, Munoz M, Balil A, Garcia-Mata J, Calvo L, Carrasco E, Mahillo E, Casado A, GarciaSaenz JA, Escudero MJ, Guillem V, Jara C, et al. Gemcitabine plus vinorelbine versus vinorelbine monotherapy in patients with metastatic breast cancer previously treated with anthracyclines and taxanes: final results of the phase III Spanish Breast Cancer Research Group (GEICAM) trial. Lancet Oncol. 2007; 8:219-25. https://doi.org/10.1016/S1470-2045(07)70041-4.

30. Pallis AG, Boukovinas I, Ardavanis A, Varthalitis I, Malamos N, Georgoulias V, Mavroudis D. A multicenter randomized phase III trial of vinorelbine/gemcitabine doublet versus capecitabine monotherapy in anthracyclineand taxane-pretreated women with metastatic breast cancer. Ann Oncol. 2012; 23:1164-9. https://doi.org/10.1093/ annonc/mdr405.

31. Papadimitriou CA, Kalofonos H, Zagouri F, Papakostas P, Bozas G, Makatsoris T, Dimopoulos MA, Fountzilas G. Weekly docetaxel with or without gemcitabine as second-line chemotherapy in paclitaxel-pretreated patients with metastatic breast cancer: a randomized phase II study conducted by the Hellenic Co-Operative Oncology Group. Oncology. 2009; 77:212-6. https://doi.org/10.1159/000236021.

32. Swain SM, Tang G, Geyer CE Jr, Rastogi P, Atkins JN, Donnellan PP, Fehrenbacher L, Azar CA, Robidoux A, Polikoff JA, Brufsky AM, Biggs DD, Levine EA, et al. Definitive results of a phase III adjuvant trial comparing three chemotherapy regimens in women with operable, node-positive breast cancer: the NSABP B-38 trial. J Clin Oncol. 2013; 31:3197-204. https://doi.org/10.1200/ JCO.2012.48.1275.

33. Vici P, Giotta F, Di Lauro L, Sergi D, Vizza E, Mariani L, Latorre A, Pizzuti L, D’Amico C, Giannarelli D, Colucci G. A multicenter phase II randomized trial of docetaxel/ gemcitabine versus docetaxel/capecitabine as first-line treatment for advanced breast cancer: a Gruppo Oncologico Italia Meridionale study. Oncology. 2011; 81:230-6. https:// doi.org/10.1159/000334432.

34. Hu Q, Jiang JX, Luo L, Yang X, Lin X, Dinglin XX, Zhang W, Wu JY, Yao HR. A systematic review of gemcitabine and taxanes combination therapy randomized trials for metastatic breast cancer. Springerplus. 2014; 3: 293. https://doi.org/10.1186/2193-1801-3-293.

35. Blumenthal GM, Scher NS, Cortazar P, Chattopadhyay S, Tang S, Song P, Liu Q, Ringgold K, Pilaro AM, Tilley A, King KE, Graham L, Rellahan BL, et al. First FDA approval of dual anti-HER2 regimen: pertuzumab in combination with trastuzumab and docetaxel for HER2-positive metastatic breast cancer. Clin Cancer Res. 2013; 19:4911-6. https://doi.org/10.1158/1078-0432.ccr-13-1212.

36. Vinayak S, Carlson RW. mTOR inhibitors in the treatment of breast cancer. Oncology (Williston Park). 2013; 27:38-44, 6,8 passim.

37. Verma S, Miles D, Gianni L, Krop IE, Welslau M, Baselga J, Pegram M, Oh DY, Dieras V, Guardino E, Fang L, Lu MW, Olsen S, et al. Trastuzumab emtansine for HER2-positive advanced breast cancer. N Engl J Med. 2012; 367:1783-91. https://doi.org/10.1056/NEJMoa1209124.

38. Crown J, Dieras V, Kaufmann M, von Minckwitz G, Kaye S, Leonard R, Marty M, Misset JL, Osterwalder B, Piccart M. Chemotherapy for metastatic breast cancerreport of a European expert panel. Lancet Oncol. 2002; 3:719-27.

39. Li W, Wang H, Li X. Efficacy of gemcitabine-based chemotherapy in metastatic breast cancer: a meta-analysis of randomized controlled trials. Curr Med Res Opin. 2013; 29:1443-52. https://doi.org/10.1185/03007995.2013.832185.

40. Vassilopoulou-Sellin R, Theriault RL. Randomized prospective trial of estrogen-replacement therapy in women with a history of breast cancer. J Natl Cancer Inst Monogr. 1994:153-9.

41. Aapro MS, Martin C, Hatty S. Gemcitabine - a safety review. Anticancer Drugs. 1998; 9:191-201.

42. Garin A, Manikhas A, Biakhov M, Chezhin M, Ivanchenko T, Krejcy K, Karaseva V, Tjulandin S. A phase II study of pemetrexed and carboplatin in patients with locally advanced or metastatic breast cancer. Breast Cancer Res Treat. 2008; 110:309-15. https://doi.org/10.1007/ s10549-007-9722-5.

43. Modi S, Seidman AD. Single-agent gemcitabine in the treatment of advanced breast cancer. Clin Breast Cancer. 2004; 4:S101-6.

44. Carrick S, Parker S, Thornton CE, Ghersi D, Simes J, Wilcken N. Single agent versus combination chemotherapy for metastatic breast cancer. Cochrane Database Syst Rev. 2009: CD003372. https://doi.org/10.1002/14651858. CD003372.pub3.

45. von Minckwitz G, Martin M, Wilson G, Alba E, Schmidt M, Biganzoli L, Awada A. Optimizing taxane use in $\mathrm{MBC}$ in the emerging era of targeted chemotherapy. Crit Rev Oncol Hematol. 2013; 85:315-31. https://doi.org/10.1016/j. critrevonc.2012.09.009.

46. Xie ZB, Jin C, Fu DL. Enhanced recovery after pancreatic surgery: a systematic review. Int J Clin Exp Med. 2016; 9:17690-702.

47. Xie ZB, Wang XB, Peng YC, Zhu SL, Ma L, Xiang BD, Gong WF, Chen J, You XM, Jiang JH, Li LQ, Zhong JH. Systematic review comparing the safety and efficacy of conventional and drug-eluting bead transarterial chemoembolization for inoperable hepatocellular 
carcinoma. Hepatol Res. 2015; 45:190-200. https://doi. org/10.1111/hepr.12450.

48. Therasse P, Arbuck SG, Eisenhauer EA, Wanders J, Kaplan RS, Rubinstein L, Verweij J, Van Glabbeke M, van Oosterom AT, Christian MC. New guidelines to evaluate the response to treatment in solid tumors. Journal of the National Cancer Institute. 2000; 92:205-16.

49. Eisenhauer E, Therasse P, Bogaerts J, Schwartz L, Sargent D, Ford R, Dancey J, Arbuck S, Gwyther S, Mooney M. New response evaluation criteria in solid tumours: revised RECIST guideline (version 1.1). European journal of cancer. 2009; 45:228-47.

50. van Tulder M, Furlan A, Bombardier C, Bouter L, Editorial Board of the Cochrane Collaboration Back Review G. Updated method guidelines for systematic reviews in the cochrane collaboration back review group. Spine (Phila Pa 1976). 2003; 28:1290-9. https://doi.org/10.1097/01. BRS.0000065484.95996.AF.
51. Tierney JF, Stewart LA, Ghersi D, Burdett S, Sydes MR. Practical methods for incorporating summary time-to-event data into meta-analysis. Trials. 2007; 8:16. https://doi. org/10.1186/1745-6215-8-16.

52. Stuck AE, Rubenstein LZ, Wieland D. Bias in meta-analysis detected by a simple, graphical test. Asymmetry detected in funnel plot was probably due to true heterogeneity. BMJ. 1998; 316: 469; author reply 70-1.

53. Sterne JA, Sutton AJ, Ioannidis JP, Terrin N, Jones DR, Lau J, Carpenter J, Rucker G, Harbord RM, Schmid CH, Tetzlaff J, Deeks JJ, Peters J, et al. Recommendations for examining and interpreting funnel plot asymmetry in metaanalyses of randomised controlled trials. BMJ. 2011; 343: d4002. https://doi.org/10.1136/bmj.d4002. 